\title{
ENTRE LA GUARACHA Y EL BOLERO: UN CICLO DE INTERTEXTOS MUSICALES EN LA NUEVA NARRATIVA PUERTORRIQUEÑA
}

\author{
POR \\ FRANCES R. APARICIO \\ University of Michigan
}

La guaracha del Macho Camacho representó en 1976 una apertura del discurso literario en la narrativa puertorriqueña. En esta novela, Luis Rafael Sánchez postuló una revolución estilística basada en la poética de lo soez y en la presencia subversiva de los ritmos populares caribeños, en particular la guaracha. Aunque la música popular ya se estaba utilizando por otros autores en esos años, La guaracha sistematizó el empleo de los códigos populares como discurso literario válido para representar la cultura puertorriqueña urbana contemporánea. ${ }^{1}$ La guaracha asumió, por igual, el lenguaje de los medios masivos de comunicación para criticarlo y parodiarlo desde dentro, estrategia que postulaba cierta ambivalencia ante el discurso de la cultura popular en Puerto Rico, ya que éste se filtra, inevitablemente, a través de la radio y la televisión, vehículos de innegable influencia norteamericana (Cruz 1985). En 1988, Luis Rafael Sánchez publica La importancia de llamarse Daniel Santos, texto aún más híbrido y ambiguo que La guaracha en cuanto crítica del "machismo" latinoamericano y de los boleros que lo alimentan. En su obra Sánchez asume el lenguaje varonil y falocéntrico del bolero y la guaracha para problematizarlo, y es en la asunción de dicho lenguaje desde dentro, paradójicamente, donde reside el placer de la lectura.

En términos diacrónicos la guaracha y el bolero representan, pues, el inicio y el apogeo de un ciclo de textos narrativos puertorriqueños en los cuales el discurso de la música popular caribeña, según se plasma en los varios géneros

${ }^{1}$ Es imperativo aclarar que antes de 1976 ya otros autores puertorriqueños habían comenzado a experimentar con la música popular puertorriqueña en sus cuentos. Entre otros, "Cuando las mujeres quieren a los hombres" de Rosario Ferré y "La última plena que bail6 Luberza" de Manuel Ramos Otero aparecieron en Zona de carga y descarga a raíz de la muerte de Isabel "La Negra" Luberza, en 1974. "Maquinolandera", cuento que cierra la colección Papeles de Pandora (1976), apareció el mismo año que Laguaracha; sin embargo, la crítica no le ha prestado la atención merecida como texto igualmente subversivo al de Luis Rafael Sánchez en cuanto a la poética que postula. La guaracha, pues, no inicia dicha tendencia interdisciplinaria, sino que la sistematiza dentro de las letras puertorriqueñas. 
y canciones, asume importancia como elemento intertextual. Esta nueva narrativa polifónica y heterogénea intenta des-velar una visión de la cultura puertorriqueña análogamente conflictiva, heterorracial y polifacética. ${ }^{2}$ Dicho ciclo se constituye por textos que exhiben, como la guaracha, una fuerza centrifuga y, como el bolero, centripeta. Esta última propone un discurso mitificador compuesto por un lenguaje unitario y centralizado que abraza las diferencias dialectales y sociales, neutralizándolas. Lenguaje esencializador, tiende a la homogeneidad en su representación. Según Bakhtin, la fuerza centrípeta sólo puede proponer un lenguaje unitario como ideal en vez de ofrecerlo como hecho concreto, ya que, a pesar de los esfuerzos centralizadores de la cultura, todo lenguaje nacional, en el fondo, consiste en una diversidad de voces sociales y estratos lingüísticos que en él convergen. Un texto centrífugo, por lo contrario, exhibiría la heteroglossia social de una época en particular. El modo dialógico presenta lenguajes en oposición a otros y problematizados por ellos. El texto centrífugo propone, entonces, una lectura abierta, desmitificadora y dispersa de la realidad (Bakhtin 270-272). La mayoría de los textos que aquí se estudian, los cuales se caracterizan por la inscripción intertextual de las voces de la música popular caribeña, exhiben una tensión entre ambos movimientos. El binomio guaracha-bolero, modelo musical, sincrónico y diacrónico a la vez, nos servirá de pauta para examinar dicha tensión según la definen los diversos intertextos musicales en la narrativa puertorriqueña.

Luis Rafael Sánchez describe el bolero por su tendencia centrípeta y la guaracha como forma de expresión centrífuga:

Opuestos que se armonizan las diferencias son el bolero y la guaracha. Y en el dinamismo de esa oposicion el Caribe instituye su bandera -el Caribe suena, suena. Curváceo pronunciamiento o teorfa y práctica del barroco es la guaracha. Inquieta por definición, huidiza si la persiguen como el fuego fatuo, incisiones prontas a las vueltas, acumulaciones eroticas que se esfuman mientras se formalizan: ahí está la guaracha. Lineal combinación que envasa su clasicismo y lo practica es el bolero. Quieto por definición, de ocurrencia bailable en la cuadrada eternidad de una loseta, sincrónica la tensión que lo embellece, acumulaciones eróticas que se concretan en una suspension de fragilidades: ahí está el bolero. La guaracha es la cacería trepidante. El bolero es el festín del cazador y la presa. La guaracha abre el cuerpo, autoriza el desplazamiento, muestra en diligentes remeneos las partes más deseables, los tramos a humedecer, los estrechos a despulpar. El bolero cierra el cuerpo, prohibe el

\footnotetext{
2 El concepto de prosa "polifónica" acuñado por Bakhtin resulta apropiado para indicar la presencia de la música popular en la nueva narrativa puertorriqueña. Para Bakhtin, la música deviene metáfora idónea para señalar un cambio central en cuanto al acto de la lectura: de una percepción visual y abstracta del texto literario a una auditiva, en la cual se escuchan las diversas y heterogéneas voces sociales de una época en particular ("heteroglossia"). Véase la definición de "polifonia" resumida al final de The Dialogic Imagination, 430 .
} 
desplazamiento, reduce la rotacion a la tentativa de una muerte vivificante. En la guaracha se extravierten las felicidades, las pasiones se ajotan de un bando y otro, se aleluyan el placer y el amor. En el bolero se recluyen las felicidades, los cuerpos se atesan y se atizan, se aleluyan el placer y el amor (Sánchez 1988, 104).

Aunque según Bakhtin dichos movimientos internos del lenguaje y del texto, el centrípeto y el centrífugo, responden a las diferencias genéricas entre poesía y prosa (285), en la literatura puertorriqueña los intertextos musicales se asocian a dos vertientes principales que ilustran no tanto los deslindes genéricos, sino más bien el contexto sociohistórico. El movimiento centrípeto, mitificador, expresado en el discurso de la nostalgia, aparece en la poesía (Tiempo de bolero de José Luis Vega, la poesf́a criollista de Luis Lloréns Torres), donde tiende a predominar, pero lo encontramos asimismo en la prosa de la Generación del 40 , en la cual el proyecto nacionalista privilegia la fuerza centrípeta del lenguaje como elemento político unificador. ${ }^{3}$ En contraste, el texto literario contemporáneo vibra en la tensión entre el bolero y la guaracha: es uno y el otro a la vez. La conexión entre el verbo, la palabra, y la ideología que satura el discurso literario, relación afirmada por Bakhtin (verbo-ideological world) nos sugiere que el texto autoritario, homogéneo y monológico de la generación de narradores del $\mathbf{4 0}$ desaparece para dar lugar a esa nueva narrativa de los 70 que, como ya ha señalado Juan Gelpí, rompe con las estructuras autoritarias, y crea una serie de textos -en su mayoria cuentosque rechazan, desmantelan y critican las viejas formas narrativas: las formas omniscientes, machistas y artificialmente nacionalistas que exhiben la tendencia unificadora y homogenizadora del lenguaje. Como instancias literarias, el mito del jíbaro y el criollismo puertorriqueño, los cuales surgen históricamente como ramificaciones de esa visión romanticoide y folklorista de nuestra cultura, se ponen en duda como modelos esencialistas, homogéneos y de vestigios europeizantes (el jibaro como fenotipo europeo y ario). Los nuevos narradores - Luis Rafael Sánchez, Rosario Ferré, Ana Lydia Vega, Carmen Lugo Filippi, Magali García Ramis, Edgardo Rodríguez Juliá, y Manuel Ramos Oteroproponen textos conflictivos y polifónicos, en cuya intertextualidad y textura heterogénea se confrontan, en modo dialógico, los diversos discursos culturales que signan nuestra realidad colonial.4

\footnotetext{
${ }^{3}$ Bakhtin 271. El texto de tendencia centrípeta inevitablemente responde a las épocas marcadas por procesos de centralización cultural, política y lingứrtica. Se verá, más adelante, dicha relación en el ámbito sociohistórico de Puerto Rico.

4 El elemento dialogico, según lo define Bakhtin, propone la lectura del lenguaje literario en constante diálogo y dialéctica con su otro, con la palabra ajena (the alien word). Dicho dialogismo interno del lenguaje se observa en la prosa puertorriqueña contemporánea, mediante la yuxtaposición del lenguaje de la clase social obrera y del proletariado con el lenguaje estilizado e intelectual del narrador autorial. El efecto dialógico se realiza no sólo en dicha confrontación intratextual, sino en la respuesta del lector, quien aporta al texto sus propios juicios e ideología del lenguaje.
} 
La música popular, comoexpresión artísticaidóneamente caribeña, responde a esa revalorización de la identidad nacional que mueve a nuestros jóvenes escritores. Rosario Ferré examina los conflictos raciales, sexuales y socioeconómicos en Puerto Rico mediante la personificación femenina de la danza y la plena en ficciones que motivan, a su vez, un nuevo examen de nuestra historia musical. El análisis paródico y desconstructor de Ana Lydia Vega sobre las relaciones entre los hombres y las mujeres en nuestros centros urbanos se codifica a través del lenguaje patriarcal de la salsa. Las observaciones testimoniales de Edgardo Rodríguez Juliá sobre los eventos colectivos en Puerto Rico y sobre el desmoronamiento de las fuentes de autoridad y del discurso del poder en nuestro país se mediatizan a través de las alusiones a la plena y la bomba. Ello se validó con el lenguaje popular urbano ficcionalizado de La guaracha... y culmina con La importancia de llamarse Daniel Santos, texto hrbrido en todos los niveles, conscientemente ambiguo y ambivalente, que explora la figura de Daniel Santos como epónimo del "macho latinoamericano" mediante un texto verbal saturado del lenguaje del bolero. Intenta, a la vez, abrirse y abrazar a Latinoamérica, crear una ontología de la "América amarga, la América descalza, la América en español ...” (5) mediante el lenguaje de la música popular.

A pesar de la singularidad del estilo de cada uno de estos autores, y de los diversos niveles intertextuales en que se inscriben las canciones y elementos musicales dentro del texto literario, todos ellos utilizan los discursos de la música popular como metáfora intertextual o, según la terminología crítica, como isótopo metafórico de una sociedad en conflicto, dividida. ${ }^{5} \mathrm{Si}$, como tan bien ha explicado Michel Foucault (90), nuestras sociedades viven en un estado de guerra no verbalizado ("unspoken warfare"), es decir, en luchas de poder y conflictos que no se expresan lingüísticamente, que no se enuncian de manera explícita, la música popular, mediatizada por el discurso literario, "nos glosa esa [la]mudez", dirá después Luis Rafael Sánchez $(1988,104)$. Al integrar la música popular dentro del textoliterario, éste último se torna mediador de la "insurrección de las formas de conocimiento subyugadas" por la cual aboga Michel Foucault (81). Más especificamente, el pensador francés propone una "genealogía" que combine "el conocimiento erudito con las memorias locales, con los contenidos históricos que han sido enmascarados bajo una coherencia funcional o bajo la

\footnotetext{
"El valor de "isotopique métaphorique" que define Laurent Jenny, 274, se establece como un fragmento textual que "est appelé dans le contexte par analogie sémantique avec lui". Los intertextos "servent à éclairer le sens d'un passage, à l'enrichir d'un jeu de souvenirs associatifs, à indiquer par la voix d'un autre une direction de lecture". Es significativo, por igual, el empleo del concepto científico "isótopo" para definir la relación entre el texto primigenio y el segundo texto que lo recibe e incorpora. El isótopo indica un lugar (topo) igual (iso) entre dos cuerpos que tienen las mismas propiedades químicas, pero cuyos átomos poseen distinta constitución y peso; ello sugiere que la intertextualidad otorga igualdad semántica a ambos textos.
} 
sistematización formal" o "con los conocimientos ingenuos que a través de la historia se han considerado inadecuados como fuentes de información sobre una cultura" (80-87; traducción del autor). La nueva narrativa propone una crítica ante la cultura oficial mediante la inscripción del conocimiento regional y a la vez diferencial que la música popular proyecta, y el cual el texto literario asume como una de las múltiples voces que lo conforman.

Los teóricos europeos de la intertextualidad han formulado la idea de que ella "pone en duda el lugar privilegiado de la literatura al integrar implícita o explícitamente toda clase de textos dentro de un sistema literario que se define a sí mismo en moción constante y, por lo tanto, potencialmente capaz de reinventar su significado infinitamente" (Hoffer Gosselin, 23; traducción del autor). En cuanto a la literatura puertorriqueña, es necesario refinar aún más esta función de la intertextualidad. Si, por un lado, como ya se ha mencionado, la presencia de intertextos implica una actitud radicalizadora ante el lugar privilegiado de la literatura, por otro, dicha intertextualidad reafirma la condición literarizada del texto moderno y contemporáneo ("la escritura de la escritura", el palimpsesto borgeano) (Rusinko 231). Ejemplificados en la obra de un Borges o de un Carlos Fuentes, los intertextos proponen un lector ideal burgués e intelectual familiarizado con el canon de las literaturas europea, norteamericana y latinoamericana. La selección de textos musicales por los narradores puertorriqueños sugiere todo lo contrario. Representa, más bien, una apertura o democratización del lector ideal puertorriqueño o caribeño (y subrayo los gentilicios para recalcar la necesidad imperante de poseer un código común en la lectura intertextual), quien reconocería los textos de la música popular sin necesidad de ser un erudito de la llamada cultura universal u occidental. Ante todo, el origen de ese texto primigenio se define en su naturaleza, y sólo entendiendo su radical diferencia con el intertexto "erudito" se puede arribar a su tipologia funcional. La presencia de los códigos de la cultura popular como elementos intrínsecos de una nueva lectura de la realidad latinoamericana - la música y la radio en Cabrera Infante, el cine y la fotonovela en Manuel Puig, los boleros y el rock en Ángeles Mastretta y en José Agustín - revela una poética diferente a la que proponen los textos literaturizantes de Borges, Fuentes, Lezama Lima y hasta de un Cortázar, obras cuyos intertextos "eruditos" conducen a un mayor hermetismo y a una resistencia a la significación en el proceso de la lectura.

Otra problemática que confronta el crítico de la literatura puertorriqueña es la necesidad de crear categorías de los varios niveles de inserción del intertexto dentro del segundo texto. Encontramos una ancha gama de niveles de inscripción musical en las narraciones estudiadas: 1) en el discurso pretextual; 2) como letras de canciones insertas en las enunciaciones de los personajes y del narrador; 3) como parte de construcciones hibridas, que en algunos casos conducen a la saturación musical del discurso literario; 4) como código metaliterario; 5) y al nivel sonoro, rítmico y cadencial de la prosa. 
La inscripción de la música en el discurso pre-textual o extra-ficcional, es decir en los títulos o epigrafes, se ejemplifica en el cuento "Cuando las mujeres quieren a los hombres”, de Rosario Ferré. La sustitución dialógica de la palabra "plena" por "puta" en la plena citada como epígrafe, "la puta que yo conozco/no es de la china ni del japón/porque la puta viene de ponce/viene del barrio de san antón", sugiere un contexto semántico mayor que el que se ha propuesto con una lectura únicamente feminista del cuento. La intertextualidad musical, en este caso, propone que la dualidad y fusión final entre Isabel Luberza e Isabel La Negra no se lea sólo como la opresión común de dos mujeres de clase social opuesta, sino como un examen de la tradición histórica musical puertorriqueña, cuya oposición tajante de la danza versus la plena se ficcionaliza a través de los dos personajes. ${ }^{6}$ Si el discurso de la plena en el cuento aparece de modo explícito (el título, el epígrafe), la danza brilla por su ausencia. Sin embargo, el valor dialógico entre ambas se conjuga en la oposición de las mujeres, la figura de Isabel Luberza, la dama blanca de la aristocracia, sugiere, pues, la presencia implícita de la danza.

Estas formas musicales han sido objeto de unafemenización (léase en sentido peyorativo) en manos de la escritura patriarcal y autoritaria de, por ejemplo, Pedreira, quien asocia lo femenino con lo puertorriqueño, con la geografía de nuestra isla, y con lo débil $(41-42,197)$. Tomás Blanco, en su ensayo "Elogio de la plena" (1935), metaforiza la danza y la plena como figuras opuestas de mujeres, una blanca, europea a lo Rubens, y la otra mulata pícara (42). El discurso literario de Ferré conforma un texto dialógico que sugiere toda una serie de subtextos oposicionales (Blanco, Pedreira, plenas tradicionales), configurando, a la vez, un contexto mayor dentro del cual podemos otorgarle significación. Así, el texto establece una ruptura con la tradición autoritaria y patriarcal gracias al elemento final de la fusión simbólica y psíquica entre Isabel Luberza e Isabel la Negra que, aunque se podría tildar de una fácil apología del mestizaje _en este caso mulatismo-, indica un rechazo de la historia oficial que dualiza la realidad en términos maniqueístas, en blanco(s) y negro(s), y que define la identidad nacional puertorriqueña en base a lo blanco y europeo. La nueva historiografía en Puerto Rico nos demuestra, como lo sugiere el texto narrativo de Ferré, que aun una forma musical como la danza, tan europea en

\footnotetext{
- Los artículos en torno a "Cuando las mujeres quieren a los hombres" se han centrado únicamente en el análisis feminista. Véanse, entre otros, los artículos citados de Margarite Fernández Olmos, "Luis Rafael Sánchez and Rosario Ferré: Sexual Politics and Contemporary Puerto Rican Narrative" y "From a Woman's Perspective: The Short Stories of Rosario Ferre and Ana Lydia Vega", y el de María Inés Lagos-Pope, "Sumisión y rebeldías, el doble o la representación de la alienación femenina en narraciones de Marta Brunet y Rosario Ferré". Dichos trabajos de aproximacion feminista, sin embargo, no toman en cuenta las implicaciones de clase y de raza en cuanto a las diferentes formas de opresión que sufre la mujer puertorriqueña.
} 
sus orígenes y tan aristocrática en su praxis, no se puede explicar sin el reconocimiento de las contribuciones musicales del sector mulato puertorriqueño: de Juan Morel Campos y Manuel Tavárez. Por ejemplo, el tresillo elástico y el empleo del bombardino, para sólo citar dos elementos que revelan la base parcialmente africana y el sincretismo que caracteriza históricamente a nuestra danza (Quintero-Rivera 34-39).

Edgardo Rodríguez Juliá, en El entierro de Cortijo (1983) y "Llegó el Obispo de Roma" (1986), inscribe asimismo el discurso musical en los títulos y epígrafes de sus textos periodísticos y testimoniales. En dichas obras, el género musical de la plena metaforiza la problemática de los discursos y fuentes del poder en la sociedad puertorriqueña, valor semántico que se vislumbra, por igual, en el cuento "La última plena que bailó Luberza" de Manuel Ramos Otero. ${ }^{7}$ En su crónica y descripción sobre el velorio y el entierro de Rafael Cortijo, el famoso plenero que reivindicó la música de los negros urbanos, los epígrafes de varias plenas populares puertorriqueñas - "Cortaron a Elena", "El bombón de Elena", "Maquinolandera" " "Dorotea" - sirven de anticipo pre-textual para lo que será un agudo análisis crítico de los cambios sociales que han sufrido los puertorriqueños a partir del "desarrollismo muñocista" de los años 40. El "desclasamiento", término que acuña Rodríguez Juliá para referirse al desmoronamiento del poder de los hacendados y a la movilidad de muchas familias del campo a la ciudad, dio lugar a una hibridez de condiciones de vida dentro del área metropolitana. Los resultados, para el narrador (que de hecho se identifica con el autor real), se revelan en su actitud irónica ante todas las clases sociales:

un individualismo feroz y una vocación solitaria que trata a todas las tribus con igual ironia; ese desclasamiento me obligo a imaginar y observar; he ahi la semilla de mi vocación literaria ... $(1983,16)$

Dicho "desclasamiento", resultado de la intervención norteamericana, fue percibido por muchos intelectuales de la Isla como la muerte de la cultura nacional puertorriqueña, o sea, la hasta entonces dominante de los hacendados. Por otro lado, como sugiere José Luis González, tal desclasamiento contribuyó al surgimiento de una cultura de masas y, por consecuencia, al desarrollo de la cultura popular en Puerto Rico (30).

\footnotetext{
${ }^{7}$ En "La última plena que bailo Luberza" de Manuel Ramos Otero, la figura de Isabel la Negra se presenta como matrona y figura autoritaria dentro del mundo lumpenizado del prostíbulo que dirigía. Se asocia la plena de su último sueño antes de morir con el contexto dictatorial en que se inserta a la protagonista, figura análoga a la Mamá Grande de García Márquez. Para otra instancia literaria en la que la plena se ficcionaliza en relación con el poder, véase de Kalman Barsy, "La leyenda del Cem", cuento premiado por Casa de las Américas en 1986, en el cual la música y el baile de la plena poseen el poder de transformar el mundo, facultad de obvias implicaciones políticas.
} 
La "revolución del negro puertorriqueño" en el ámbito cultural, elemento integral al "trastocamiento interno de valores culturales" que examina José Luis González (30), se concretiza en la popularidad de Rafael Cortijo y su Combo, allá para la década de 1950. Tanto por programas de televisión ( $L a$ taberna india) como mediante los discos, la presencia visual y musical del negro amenaza para entonces el "blanquitismo" de los clubes sociales y los salones de baile, además de que transforma la visión sencilla y aparentemente ingenua de las plenas tradicionales grabadas por Manuel "Canario" Jiménez. ${ }^{8}$ La música de Cortijo representa la reivindicación y la recuperación de la plena por parte del sector negro, del cual surgió originalmente en los cañaverales y las costas de la isla entre los esclavos traídos del Africa. Además, Cortijo inicia lo que será la tradición del combo, conjunto que se antepone a la orquesta; ésta, que se origina en el período romántico, armoniza y jerarquiza los instrumentos, ejecutando la música bajo las pautas y la formalidad de una partitura, aquél representa una pluralidad de ritmos en los diversos instrumentos, verdadera polifonía de voces en la cual cada instrumento mantiene su individualidad.

La revolución de Cortijo, dentro del mundo musical puertorriqueño, implica asimismo una descentralización del significante en el texto musical:

"El bombon de Elena", composicion del Viejo Cepeda, era el tema de Cortijo y su Combo, el eslabón femenino con la música del Gran Manuel Jiménez. La Elena proletaria de Canario, aquel paradigma de la plena antigua cuya concreción siempre parte de una anécdota y algunos detalles felices, aquí se ha convertido en soneo vago, quizás más sugerente, definitivamente más irónico: la plena abandona el contorno proletario y se acerca a los límites imprecisos de un lenguaje en clave, para iniciados, jerga del exclusivismo lumpen del arrabal y el caserío. Toda la música de Cortijo es así, rica en connotaciones malevas y pobre en denotaciones realistas. (Rodríguez Juliá, 1983, 70-71)

Juliá ejemplifica este cambio semántico en las canciones de Cortijo:

A nadie le interesa (la caña que chupaba Perico, en "Quítate de la vía, Perico"): la clave, o la ausencia de ésta, forma todo el significado, o casi todo; la anécdota ha perdido su valor de crónica, se ha resquebrajado el mundo proletario, ya apunta en esta plena el codigo de las composiciones salseras niuyorkinas, ese jaleo inseguro entre la evocación de un parafso caribeño que ya no es, que nunca fue, y la clave oculta en la picaresca de callejón $(1983,71)$.

${ }^{8}$ La investigación de Jorge Pérez Rolón sobre el desarrollo histórico de la bomba y de la plena indica que la aparente sencillez o ingenuidad de la plena tradicional es sólo eso, apariencia. Pérez Rolón demuestra cómo la perspectiva aguda, burlona y crítica del pueblo ante los eventos históricos en Puerto Rico se disfraza bajo ese lenguaje sencillo en la superficie. Además, el trabajo más reciente de Juan Flores sobre la plena sugiere que un examen de este género implicaría toda una nueva revaloración de lo que se ha denominado plenas tradicionales o anonimas, las cuales sí parecen haber tenido autor, muchas de ellas en la persona de Bumbún Oppenheimer. 
No nos hemos detenido en esta extensa cita sin razón. Nótese el análisis de una transformación semántica dentro del lenguaje de la plena: de un lenguaje anecdótico y representativo que se plasma en las plenas tradicionales de Manuel "Canario" Jiménez, a unlenguaje más connotativo, con menos referencias a la realidad externa, desplazador, ironizante y centrífugo.

Dichas observaciones se podrian aplicar igualmente a la narrativa puertorriqueña, la cual rechaza esa autoridad centralizada a favor de una escritura descentrada y ambigua que minimiza, muchas veces, su anclaje en una realidad externa u objetiva. El discurso musical ironizante, centrifugo y connotativo de la plena de Cortijo contamina, pues, la narrativa anti-crónica de un Rodríguez Juliá, en la cual la presencia del narrador es siempre autoconsciente, ironizando su propia marginalidad como "blanquito" que participa en eventos colectivos del pueblo puertorriqueño: el entierro de Cortijo y la visita del Papa. ${ }^{9}$ En cuanto a los temas de la plena tradicional, recordemos que se centraban en eventos históricos percibidos a través de los ojos del pueblo, comentados con burla y sarcasmo, tono que mantiene continuidad con los textos de Rodríguez Juliá.

Cabe mencionar la importancia del lenguaje de la plena de Cortijo en lo que será, para la década de los 60 , la Salsa, expresión híbrida en cuanto a su base de identidad (música de puertorriqueños en Nueva York, música de minorias oprimidas, música que nace del Barrio) (Rondón, 30-33). No es arbitrario, pues, que los epígrafes musicales de Rodríguez Juliá apunten hacia un nuevo modo de leer la sociedad y la cultura puertorriqueña, como si fuera un texto descentrado y polifónico, en el cual las voces y el lenguaje del sector negro, de Barrio Obrero, de los llamados títeres de Lloréns Torres, asuman un papel dialógico frente al discurso homogeneizante del blanco. Ante la pérdida de poder delas autoritarias fuentes oficiales puertorriqueñas (ilustrada por la superioridad que ejerce el Servicio Secreto norteamericano sobre la policía local durante la visita del Papa, en "Llegó el Obispo de Roma"), tanto la Iglesia como el sistema de consumo norteamericano imponen sus propios canales de guerra y de luchas de poder. Dichas instituciones se enfrentan constantemente con las masas, con el pueblo puertorriqueño, inscribiéndolos ya sea en espacios divididos (como hacen con la "puesta en escena" del Papa en el estacionamiento de Plaza las Américas), o mediante la estratificación del lenguaje. Como contra-estrategia a dichas maniobras de poder, surgen las voces del barrio, de los pobres, de los marginados. Los chistes sobre el Papa en que se filtra el "ancestral sentimiento anti-clerical"

\footnotetext{
- El lenguaje descentrado e ironizante de las plenas de Cortijo asimismo se muestra en vigor en el cuento "Maquinolandera" (1976) de Rosario Ferré, cuyo título nos remite precisamente a una bomba del mismo nombre compuesta por Doña Margarita Rivera e interpretada por Cortijo y su Combo e Ismael Rivera. El valor onomatopéyico y metalingúistico de la bomba le otorga significación a la prosa, revelándola como texto en el que se plasma una bú squeda ontologica de la palabra análoga a la búsqueda del sonido para el músico compositor.
} 
(Rodríguez Juliá, 1983, 13), el discurso sexual a lo "mamichulin" dirigido a las mujeres, la perspectiva burlona y satírica hacia la autoridad que se filtra en la plena tradicional - "Mamita llegó el Obispo, llegó el Obispo de Roma, Mamita si tú lo vieras, Qué cosa linda, que cosa mona" - se anteponen de modo dialógico a la música tradicional y mistificadora de la Iglesia ("Bendito, bendito, bendito sea Dios"). Dicho lenguaje popular, que no se puede separar del discurso musical caribeño, es precisamente el que los autores contemporáneos de Puerto Rico han reivindicado en su narrativa, desde la poética de lo soez de Luis Rafael Sánchez y el lenguaje de la calle que utiliza Ana Lydia Vega en algunos de sus cuentos, hasta el lenguaje erótico, abiertamente sexual y transgresor de un Manuel Ramos Otero o del mismo Luis Rafael Sánchez.

Aunque el discurso de la Salsa se origina en los barrios de Nueva York, influye plenamente en las vidas de los habitantes de los barrios del Caribe, desde Cali, Colombia, pasando por La Habana, Cuba, hasta llegar más allá de Nueva York, a las costas californianas de Los Ángeles y San Francisco. Si el lenguaje violento, agresivo, $y$ "vulgar" de las composiciones salseras representó, por un lado, una respuesta contestataria al estilo lírico y refinado de los boleros latinoamericanos, a la vez vocalizó las penas, sufrimientos y opresiones que sufre el individuo del barrio. Al nivel ideológico, sin embargo, la Salsa comparte con el bolero la perspectiva patriarcal y la actitud agresora y acusatoria ante la mujer (Malavet Vega, 393-409).

Ana Lydia Vega y Carmen Lugo Filippi emplean este discurso como el lenguaje de sus personajes varones para desmitificarloy desconstruirlo, mediante el uso de la parodia y la crítica incisiva que se asoman en la voz narrativa autorial. Al nivel de la inscripción de la música popular como intertexto, los cuentos "Letra para salsa y tres soneos por encargo", $y$ "Cuatro selecciones por una peseta" representan una saturación mayor del discurso musical dentro del texto literario. Además de la presencia musical en los títulos y epígrafes, la música se integra en el primer cuento como parte de su ideología y de su estructura; en el segundo, aparece como el lenguaje del "otro" ("alien word"), del cual los cuatro hombres puertorriqueños se apropian para poder expresar sus realidades emotivas.

"Cuatro selecciones por una peseta", escrito en colaboración por Ana Lydia Vega y Carmen Lugo Filippi, anticipa y proyecta en su epígrafe "Así son, así son las mujeres", texto de la canción interpretada por El Gran Combo de Puerto Rico, la perspectiva masculina que predominará a través del cuento. El subtítulo, "Bolero a dos voces para machos en pena, una sentida interpretación del dúo Scaldada-Cuervo" nos revela la perspectivaironizante y desmitificadora de la voz narrativa autorial. De hecho, los subtextos (en este caso utilizamos el término para referirnos al texto que sirve como fuente, "source-text") de dicha canción y del cuento son, predominantemente, boleros. El bolero se caracteriza por el tema de la ausencia de la mujer que da lugar a la necesidad de catarsis por parte del hombre. Con frecuencia, dicha catarsis tiene lugar en una barra 
o club nocturno, luego de una borrachera. Los textos de los boleros están inundados, por así decirlo, con referencias al licor y reafirman la necesidad del hombre de emborracharse para olvidar (Malavet Vega, 393-409).

En el texto de Vega y Filippi, escuchamos las voces de cuatro amigos Eddie, Angelito, Monchín y Puruco- reunidos en una barra y ellos, a su vez, escuchan música en la vellonera: boleros, tangos, rancheras y salsa, mientras que cada uno expresa, mediante monólogos reveladores, sus quejas sobre la mujer. ${ }^{10}$ En todos los casos el lector se entera de que sus mujeres los han abandonado, con la excepción de Angelito, que es soltero. Lo que a primera vista se puede leer como quejas sobre las mujeres son las voces de los hombres construyendo a la mujer, diatribas que se logran gracias al discurso de la música que están escuchando. Dichos personajes no tienen un lenguaje propio, sino que constantemente se apropian de los textos cancioneriles de la música popular. Desde tal perspectiva, el cuento presenta una crítica a las estrategias comerciales utilizadas por los medios masivos de comunicación y por la industria musical, instituciones que manipulan el lenguaje y, consecuentemente, la conciencia e ideología del público auditorio. Mediante la repetición y la estandarización de ciertas canciones claves, según Theodor Adorno, la industria musical crea un público auditorio conforme y pasivo que acepta los mensajes de las canciones de manera indiscriminada (42). En el caso de los cuatro hombres puertorriqueños, la música popular se convierte en código ajeno y, paradójicamente, necesario para ellos poder verbalizar sus propias realidades sentimentales.

El elemento dialógico del texto de Vega y Filippi se revela en la dinámica y en los intersticios entre las diatribas de los hombres y la voz narrativa que los va parodiando despiadadamente. Mediante la ironía y el humor, los lectores se dan cuenta que estos hombres en realidad les son infieles a sus mujeres, se comportan como niños mimados por sus madres, y poseen una ignorancia e ingenuidad sorprendentes ante la situación política y social puertorriqueñas. La óptica femenina que subyace las diatribas y que problematiza las palabras de estos hombres, nos revela que el texto es una lectura sobre los hombres y no sobre las mujeres. "Así son, así son los hombres cuando lloran (o cuando no pueden llorar)" sugeriría un título más adecuado en cuanto a la ideología que se esconde detrés de las palabras.

En "Letra para salsa y tres soneos por encargo" encontramos un intento de desmitificar las convenciones sociales relacionadas con las divisiones de clase, raza y roles sexuales. En este texto de Ana Lydia Vega el discurso musical de la Salsa apunta a una ideología opuesta a la que verbaliza la Salsa en el cuento anterior. En este caso, el epígrafe de Pedro Navaja, de Rubén Blades, "La vida

\footnotetext{
${ }^{10}$ No es coincidencia que la música de la vellonera que los personajes escuchan represente cuatro géneros principales de la canción latinoamericana: el bolero, el tango, la ranchera y algunas canciones de Salsa. Ellos comparten el topos del hombre emborrachándose para olvidar a la mujer que lo abandonó.
} 
te da sorpresas, sorpresas te da la vida", anticipa un discurso concientizador que se refleja en el texto literario. ${ }^{11} \mathrm{El}$ epígrafe de Pedro Navaja nos remite, pues, a la obra dramática, en cuya introducción o prefacio, el narrador se pasea por los pasillosy señala a variosindividuos en el públicoinformándoles de situaciones chocantes: "Su esposa se escapó con el jardinero", "Su hijo es homosexual", es decir, situaciones que obligan al espectador a aceptar la ruptura de los moldes sociales y que lo conducen al margen de lo aceptado y lo correcto.

En el texto de Ana Lydia Vega se logra igualmente ese efecto desmitificador del hombre puertorriqueño. Una "Tipa" recoge a un "Tipo" en la calle y, luego de llegar al cuarto del motel donde tendrán relaciones sexuales, el Tipo se indispone y no puede ejecutar el acto sexual o, no puede, en términos musicales, salsear. A diferencia del texto cerrado, que nos ofrece una posible interpretación de la realidad, el texto de Vega propone tres finales posibles, variantes que se denominan "soneos". El soneo, dentro del desarrollo estructural de la Salsa y de la música caribeña, representa la naturaleza dialógica e improvisadora del texto musical, libertad que se refleja en la estructura abierta del final del cuento y que invita, además, a un diálogo entre el lector y el texto. ${ }^{12} \mathrm{Al}$ implicar que ni el materialismo dialéctico (propuesto en el primer soneo), ni el feminismo (del segundo soneo), en cuanto paradigmas culturales, son respuestas exclusivas a esta guerra conflictiva entre los hombres y las mujeres en Puerto Rico, el tercer soneo sugiere una estructura circular al texto. Dicho final recalca la impotencia metafórica del hombre puertorriqueño, su incapacidad de ajustarse, adaptarse y transformarse a los cambios que la mujer puertorriqueña ya ha logrado. Es, pues, una impotencia polisémica que el lector interpreta gracias al final del cuento. El Tipo regresa a su lugar de origen en las aceras de Santurce, y vuelve a utilizar su discurso como carnada para seducir a otra mujer. Sin embargo, el lector lee ese discurso vaciado ahora de todo su aparente poder, un discurso constituido por códigos y gestos que enmascaran su verdadera falta de poder. En "Letra para salsa y tres soneos por encargo", el discurso musical funciona, pues, no sólo como lenguaje que revela la ideología desmitificadora de la lucha entre las expectativas del hombre y la mujer impuestas por las convenciones sociales, sino que también sirve como recurso estructurador de la obra abierta.

\footnotetext{
${ }^{11}$ Hoy día no se puede hablar de la Salsa en cuanto discurso monolítico, sino como diversos lenguajes que corresponden a las divergentes ideologias de las cuales surgen. Hay textos concientizadores, políticamente conservadores, patriarcales y misóginos, violentos, románticos, de humor, eróticos y cristianos.

${ }^{12}$ Michael H. Handelsman, en su artículo "Desnudando al macho: un análisis de 'Letra para salsa y tres soneos por encargo", define el soneo como "una especie de estribillo que se repite a lo largo de la salsa y, por lo general, destaca el tema central de la pieza" (562). Asocia las tres variantes del final del cuento con el epigrafe de Rubén Blades. Dicha definición, sin embargo, es parcial e incompleta. El soneo no es sólo el estribillo que recurre a través de la canción, sino el díalogo que se establece entre el solista y los instrumentos y el espacio de improvisacion que se estructura alrededor del estribillo.
} 
El valor metafórico de la música popular, y en particular, del bolero y de la guaracha comoindicadores de las relaciones entre el hombre y la mujer, culmina en la última obra de Luis Rafael Sánchez. Quizás el texto más musical de los estudiados hasta ahora, La importancia de llamarse Daniel Santos (1988) representa el apogeo de la intertextualidad musical en la prosa puertorriqueña y, a la vez, una apertura y extensión de los códigos de nuestra música popular hacia todo el continente latinoamericano (Fernández).

Sugerida por el título mismo, que tiene como intertexto la obra de Oscar Wilde, The Importance of Being Earnest, la intertextualidad constituye la base del discurso literario, ya que la obra es una suma de citas, alusiones y referencias a textos anteriores, desde Shakespeare y Homero hasta Darío y Neruda. Se vislumbra una hibridez textual en todos los niveles semánticos: desde su fusión de géneros (es crónica anticronística, biografía fabulada, narraciones incompletas, ensayo, repertorio de canciones), hasta su hibridez de estratos lingüísticos. Los códigos más rebuscados de la literatura occidental se funden y se "contaminan" con las letras de los boleros de Daniel Santos, Pedro Flores, Agustín Lara y Rafael Hernández, y con el lenguaje popular y "soez" del lumpen latinoamericano. En esta obra la heteroglossia a la que se refiriera Bakhtin se concretiza en forma ejemplar.

El discurso predominante del texto es, sin embargo, aquel constituido por las letras de boleros y guarachas interpretadas por Daniel Santos. Como mencionamos anteriormente, dicha intertextualidad, tan auténticamente explorada por los escritores latinoamericanos, democratiza el texto literario validandoel lenguaje musical popular como código artístico nuestro y reactivando, en este caso, el sentido humano y universal de los boleros. Se exhibe una tensión entre la comunalidad de las canciones y su singularidad como expresión musical originada en los barrios urbanos latinoamericanos. Las canciones que, desde la década de 1930 en adelante, apelan tanto a los sentimientos románticos del "macho burgués de Garden Hills", el "Crema", como al individuo de Barrio Obrero y al lumpen latinoamericano, el "Mierda", y sirven de nexo a ese sentir del macho, ese "vivir en varón", que informa como hilo unitivo todo el tejido textual. El "diálogo imposible" de clases en esta obra ocurre mediante las letras de los boleros, las cuales contienen una actitud común hacia la mujer, de despecho y de dependencia, de idealización y de acusación, de amor y de odio, discurso contradictorio y ambiguo que une "solidariamente" al hombre latinoamericano de todas las clases sociales.

La ambivalencia del discurso de Luis Rafael Sánchez, que también caracterizó su primera novela, La guaracha del Macho Camacho, satura su obra sobre Daniel Santos. El problema de la doble identidad, de una identidad real escondida bajo las máscaras de otra identidad creada (tema central del subtexto de Oscar Wilde) sugiere una relectura del varón latinoamericano como texto definido por una tensión interna entre las dos identidades sexuales dentro del hombre, lo masculino y lo femenino. Dicha ambivalencia signa todo el texto 
literario. Mustrada en la descentralización del ego de Daniel Santos, dicha ambigüedad es característica, según Julia Kristeva, de la figura de Don Juan, quien, en su intento de seducir un sinnúmero de mujeres, escapa la unicidad y encarna la multiplicidad, de ahí su condición polifónica (192-194).

La ambigüedad del texto, marcada por una tensión entre la fuerza mitificadora del bolero (y la música glorificada como la expresión artística que "nos glosa la mudez" y que nos invita a la sensualidad), y la fuerza centrífuga de la guaracha, la visión desmitificadora del machismo, de la historia y de la literatura como tal, se replica en las construcciones hibridas que lo configuran: "Hacia la bohemia como sistema. Hacia la vellonera como recetario para incautos. Hacia La Noche Nuestra Que Está Acá en los Suelos. Hacia los mil y un tic del macho" (85). Construcciones híbridas en cuanto revelan dos sistemas axiológicos de creencias que se intersectan dentro de la misma unidad semántica (Bakhtin 305), dichas frases encapsulan las contradicciones ideológicas que forman la cultura y la vida diaria de los puertorriqueños. La figura de Daniel Santos es ícono de tales contradicciones: si el público latinoamericano lo deifica y beatifica como héroe cultural, es precisamente porque en su música y en su modo de cantar:

se infieren las gesticulaciones desgarradas del que rod6 por ahi, del que se vio en la necesidad de ponerle banderillas a la vida, del que un chispo de bienestar le costo el triple que a la humanidad restante, del que esforzó el esqueleto para sobrevivir (85).

En cuanto al ciclo de textos musicales del cual viene a formar parte esencial, Daniel Santos representa la suma y la cima de la presencia de la música en la literatura, y la máxima ambigüedad, o tensión dialógica entre el individuo y la sociedad, entre el hombre y la mujer, entre el bolero y la guaracha, entre lo centrípeto y lo centrifugo.

$\mathrm{Si}$ en términos ideológicos, y en el contexto sociohistórico, los nuevos narradores puertorriqueños han reivindicado, rescatado y transformado los discursos de la música popular (al otorgarle un significado revitalizado dentro del texto literario), y en algunos casos los han parodiado, hay que señalar que el lenguaje musical ha tenido un impacto enorme en el desarrollo de la prosa narrativa puertorriqueña. Ello se revela en cuanto contaminación estilística (aspecto que no hemos examinado aquí) pero, de mayor importancia, en la postulación de la literatura como un recurso polifónico, híbrido y autocontradictorio que contenga la pluralidad de voces y discursos que caracterizan nuestra cultura colonial urbana y contemporánea.

Mientras que la nueva narrativa ha tenido éxito como mediadora de "la insurrección de los conocimientos subyugados" por la historia oficial, los poderes de la música en cuanto vehículo mediatizante de nuestra identidad tanto personal como colectiva recobran fuerza en el texto literario. Según las palabras de Luis Rafael Sánchez, la música, como lenguaje no verbal, en conjunción con 
los textos de las canciones que escuchamos, nos traduce, es decir, ayuda a interpretarnos a nosotros mismos, a leer nuestras experiencias en el lenguaje de un "otro" que también es uno mismo. Ala vez, nos consume, nos traga, digiere y nos destruye, como vimos en el caso de los personajes de Ana Lydia Vega. Acaso lo más significativo de todo ello es que la música es un lenguaje que nos "enerva la labia" y "nos glosa la mudez", que paradójicamente nos quita la palabra y nos la otorga (Sánchez, 1988, 101).

El ciclo de textos aquí estudiados, y otros más que quedan por examinar, nos hablan a través de la música, insertándonos en esos intersticios entre la guaracha y el bolero, entre el mito y la desmitificación, entre lo centrífugo y lo centrípeto, en esos "vaivenes" semánticos y culturales que bailamos todos los puertorriqueños.

\section{OBRAS CONSULTADAS}

Adorno, Theodor. "On Popular Music". Studies in Philosophy and Social Science 9 (1941) 17-48.

Bakhtin, Michael M. "Discourse in the Novel".The Dialogic Imagination, ed. Michael Holquist. Austin, TX: University of Texas Press, 1981.

Barradas, Efraín. Para leer en puertorriqueño: acercamiento a la obra de Luis Rafael Sánchez . Río Piedras: Editorial Cultural, 1981.

Barsy, Kalman. "La leyenda del Cemi". Del nacimiento de la isla de Boriken . La Habana: Casa de las Américas, 1986.

Blanco, Tomás. "Elogio de la plena (variaciones boricuas)". Revista Ateneo Puertorriqueño 1 (1935) 97-106. Reimpreso en la Revista del Instituto de Cultura Puertorriqueña 84 (julio-sept. 1979) 39-42.

Cruz, Arnaldo. "Repetition and the Language of the Mass Media in Luis Rafael Sánchez's La guaracha del Macho Camacho". Latin American Literary Review 26 (July-Dec. 1985) 35-48.

Fernández, Enrique. 'The Importance of Being Macho: Luis Rafael Sánchez's Dangling Signifier". The Village Voice (February 28, 1989) 48.

Fernández Olmos, Margarite. 'Luis Rafael Sánchez and Rosario Ferré: Sexual Politics and Contemporary Puerto Rican Narrative". Hispania 70 (marzo, 1987) 40-46.

Fernández Olmos, Margarite. “From a Woman's Perspective: The Short Stories of Rosario Ferré and Ana Lydia Vega". Contemporary Women Authors of Latin America: New Essays, eds. Doris Meyer y Margarite Fernández Olmos. Brooklyn: Brooklyn College Press, 1983, 78-90.

Ferré, Rosario. Papeles de Pandora (México: Joaquín Mortiz, 1976).

Flores, Juan. "Bumbún and the Beginnings of La Plena". New York's Centro de Estudios Puertorriqueños Bulletin 3 (Spring 1988) 16-25.

Foucault, Michel. "TwoLectures". Power/Knowledge: Selected Interviews and Other Writings 1972-1977, ed. Colin Gordon. New York's Pantheon, 1980. 
Gelpi, Juan. "Relectura de Insularismo de Antonio S. Pedreira". Ponencia leída en la Convención de la Modern Language Association (Diciembre, 1988).

González, José Luis. El país decuatro pisos y otros ensayos . RíoPiedras: Ediciones Huracán, 1984.

Handelsman, Michael H. "Desnudando al macho: un análisis de 'Letra para salsa y tres soneos por encargo". Revista/Review Interamericana 12 (Winter 1982-83) 559-564.

Hoffer Gosselin, Claudia. "Voices of the Past in Claude Simon's La Bataille de Pharsale". Intertextuality: New Perspectives in Criticism, New York Literary Forum 2 (1978) 23-34.

Jenny, Laurent. "La strategie de la forme". Poetique: Revue de theorie et d'analyse litteraires 27 (1976) 257-281.

Kristeva, Julia. "Don Juan or Loving to be Able to". Tales of Love. Trad. León S. Roudiez. New York: Columbia University Press, 1987.

Lagos-Pope, María Inés. "Sumisión y rebeldía: el doble o la representación de la alienación femenina en narraciones de Marta Brunet y Rosario Ferré". Revista Iberoamericana 132-133 (julio-diciembre 1985) 731-749.

Malavet Vega, Pedro. La vellonera está directa. Felipe Rodríguez (La Voz) y los años 50. Río Piedras: Ediciones Huracán, 1987.

Pedreira, Antonio S. Insularismo. San Juan: Biblioteca de Autores Puertorriqueños, 1942.

Pérez-Rolón, Jorge. "La bomba y la plena puertorriqueñas: ¿sincretismo racial o transformación histórico-musical? Anales . Habana: Centro de Estudios del Caribe, 1988.

Quintero-Rivera, Ángel. "Music, Social Classes, and the National Question in Puerto Rico". Centro de Investigaciones Sociales, Universidad de Puerto Rico, 1987.

Ramos Otero, Manuel. "La última plena que bailó Luberza". El cuento de la mujer del mar. Río Piedras: Ediciones Huracán, 1979, 49-68.

Rodríguez Juliá, Edgardo. El entierro de Cortijo . Río Piedras: Ediciones Huracán, 1983.

Rodríguez Juliá, Edgardo. "Llegó el Obispo de Roma". Una noche con Iris Chacón . Río Piedras: Editorial Antillana, 1986.

Rondón, César Miguel. El libro de la salsa: crónica de la música del Caribe urbano . Caracas: Editorial Arte, 1980.

Rusinko, Elaine. "Intertextuality: The Soviet Approach to Subtext", Dispositio 11-12 (verano-otoño, 1979) 213-235.

Sánchez, Luis Rafael. Laguaracha delMacho Camacho. Buenos Aires: Ediciones de la Flor, 1976.

Sánchez, Luis Rafael, La importancia de llamarse Daniel Santos.. Hanover, New Hamsphire: Ediciones del Norte, 1988.

Vega, Ana Lydia y Carmen Lugo Filippi. Vírgenes y mártires Río Piedras: Editorial Antillana, 1983. 
Vega, José Luis. Tiempo de bolero . Río Piedras: Editorial Cultural, 1985. Wilde, Oscar. "The Importance of Being Earnest". Selected Writings of Oscar Wilde, ed. Russell Fraser. Boston: Houghton Mifflin, 1969, 208-261. 
